\title{
TECHNOLOGICAL PROGRESS TOWARDS SUSTAINABLE DEVELOPMENT
}

\author{
Klaassen Ger; Miketa; Riahi Keywan; Schrattenholzer Leo \\ Environmentally Compatible Energy Strategies (ECS) Project, International Institute for \\ Applied Systems Analysis (IIASA), Austria \\ info@worldenergy.org
}

\section{INTRODUCTION}

The range of possible long-term developments of the global energy system is indeed rather extensive. Since the first oil price hike of 1973 at the latest, research groups all over the world have begun to systematically explore this range by developing global scenarios that were intended as guidelines for energy policy making. Quite understandably, the main concern of scenario building in the 1970s was the perceived scarcity of primary energy resources, and many scenarios portrayed a rather gloomy picture of a global economy running out of vital energy. As it turned out, the initially projected gap between energy demand and energy supply was not only closed analytically, today's scenarios also include a wide range of different primary energy mixes. The limiting factor of unrestrained expansion of the energy system is thus no longer the physical availability but rather believed to be the carrying capacity of the global environment.

The most visible global environmental problem is the threat of catastrophic climate change due to the consequences of ever-increasing atmospheric concentrations of greenhouse gases (GHGs). The Kyoto Protocol of the Framework Convention on Climate Change (UNFCCC) was designed as a first significant step to tackle this problem. It remains to be seen whether the outstanding issues will be resolved in a way that will lead to the ratification of the Protocol. Nonetheless, whether it will be ratified or not, the threat of adverse climate change remains.

The problem is very long-term, however, and it is not so obvious how short-term goals such as the targets of the Kyoto Protocol contribute to the long-term solution. The answer to this question is open because the Kyoto targets are neither sufficient nor necessary for stabilizing atmospheric concentrations of GHGs at safe levels.

In this paper, we take a long-term view and follow up on the optimistic part of our argument by assuming that reaching the Kyoto targets is not necessary to avoid a global climate catastrophe, provided of course, that the overall target of an environmentally compatible development of the global energy system is actively pursued. Consistent with this assumption, we first analyse a comprehensive set of global energy scenarios with respect to an even more general concept of environmentally benign strategy sustainable development (SD). We then identify key features of SD scenarios and characterize in general terms policies that may actually contribute to the realization of such scenarios. 
The general concept of sustainable development has given rise to many qualitative and some quantitative definitions, some of them ideal and some of them more practical. In the absence of a universally agreed definition of sustainable development and aiming at criteria that can be applied to an existing set of global energy-economyenvironmental (E3) scenarios, we have come up with a working definition of sustainable development that will serve as a basis for our scenario classification.

The conclusions of our scenario analysis are mainly in the technology area, the main result of this analysis being an example of technologies that seem particularly promising to achieve sustainable development. Nevertheless, technological progress is crucial not only on the supply side but also on the end-use side of the energy system. Having thus identified technology as the key to sustainable development in fact to any kind of development we then describe dynamics of technological progress that, in our view, could be deployed by policy makers to actually reach the aspired target. In conclusion, we report on first steps to quantify the effect of research and development on technological progress.

\section{GLOBAL ENERGY ECONOMIC ENVIRONMENT SCENARIOS}

In recent years, the main albeit not the only driving force behind the formulation of global energy-economic-environment (E3) scenarios was the increasing political and research interest in global warming. Most of the recent scenarios therefore cover a time horizon of a century or more. A comprehensive effort to collect as many representative scenarios as possible was made during the work to produce the Special Report on Emissions Scenarios (SRES) for the Intergovernmental Panel on Climate Change (IPCC, Nakićenović et al., 2000). One result of this effort is a database that includes more than 400 scenarios from more than 170 literature sources, also known as the SRES database (Morita and Lee, 1998).

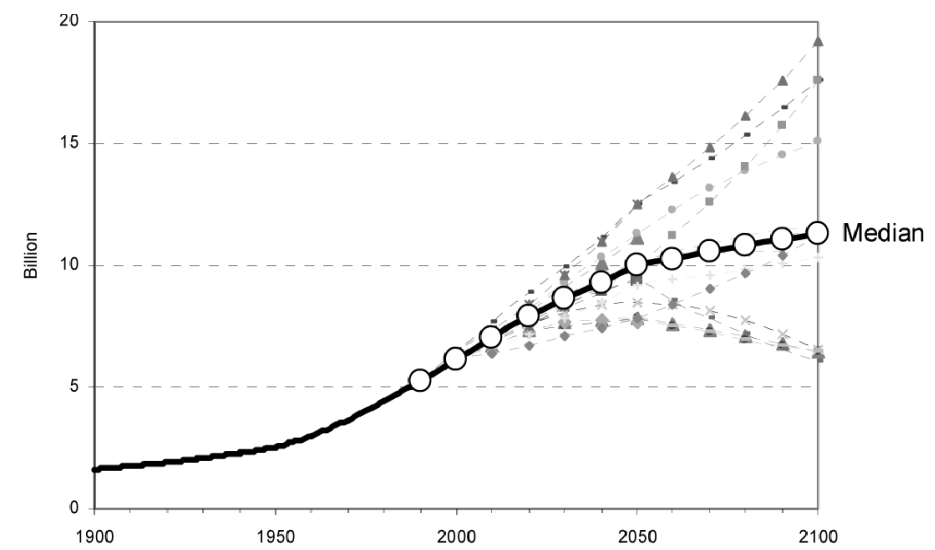

Figure 1: Global population, development from 1900 to 1990 and in 46 scenarios from the SRES database (1990 to 2100). Source of historical data: Durand, 1967; Demeny, 1990; UN, 1996; Database: Morita and Lee, 1998. 
The purpose of the SRES database was to serve as a basis for a better understanding of the main forces driving the development of the global E3 system. In this section this exercise is repeated in a very abridged means. We present distributions of key variables of the SRES database scenarios, mainly population, economic development, primary energy, and carbon emissions. Our overview does not attempt to explain the differences between different scenarios, just documenting them.

\subsection{Population}

Just a limited number of SRES database scenarios report on population. Figure 1 illustrates the global population trajectories of the 46 SRES database scenarios that report their population projections. The range for all scenarios is from less than 7 to about 18 billion $\left(10^{9}\right)$ people in 2100 with the median estimate in the range of about 11 billion. Despite this large variability, the range of change of this variable relative to the base year is the smallest of all driving forces included in this summary. Relative to 1990, global population in 2100 varies by factors of between less than one and approximately four.

The average long-term historical population growth rate has been in the order of one percent per year during the last two centuries and about 1.3 percent per year since 1900. Currently, the worlds population is increasing at about two percent per year. All SRES database scenarios and other global population projections envision a slowing population growth in the future. The lowest average population growth rate across all projections is 0.1 percent per year, the highest is 1.2 percent per year, and the median is approximately 0.7 percent per year.

\subsection{Economic development}

Figure 2 shows the future development of gross domestic product (GDP) per capita in the scenarios of the SRES database together with the past development of this variable. ${ }^{1}$ Since 1950 , GDP per capita has grown at an average annual growth rate (AAGR) of approximately two percent; in the database scenarios the AAGRs between 1990 and 2100 range from 0.4 to 2.2 percent per year, with the median value of 1.6 percent. Relative to 1990, GDP per capita in 2100 increases by factors between 1.5 and more than 12. Combining these per-capita values with the population projections, we arrive at a range with a low end at approximately US\$65 and a high end of more than US\$700 trillion (10 12 ) by 2100 (with the median GDP of US\$250 trillion). ${ }^{2} 90$ percent of the SRES database scenarios project global GDP values in 2100 that are between US $\$ 180$ and 380 trillion. The insert of Figure 2 illustrates some of the relationships between population and GDP per capita in the scenarios. Generally, higher GDP per capita goes along with lower global population projections.

\subsection{Primary energy}

Figure 3a shows primary energy consumption projections of the SRES database scenarios and the development between 1900 and 1990. On average, global primary

1 Note in this paper GDP refers to global gross domestic product.

2 All monetary values in this report are expressed in US dollars at 1990 prices unless otherwise indicated. 
energy consumption has increased at more than two percent per year (consumption of fossil energy has risen at almost three percent per year) since 1900. In the database scenarios, the average annual growth rates between 1990 and 2100 range from 0.1 percent to 2.1 percent with a median value of 1.3 percent. This means that with the exception of a few noticeable outliers, energy consumption growth projected in the database scenarios is significantly lower than the historical trend. Most scenarios project primary energy consumption levels between 500 and 3,000 exajoules (EJ) with a median near 1,500 EJ in 2100 .

More so than the absolute levels of primary energy, primary-energy intensity of GDP is an indicator of technological progress in the energy system. In all scenarios, economic growth outpaces the increase in energy consumption, often leading to substantial reductions in the ratio of primary energy consumption of GDP. Typically, higher GDP growth rates correspond to a steeper decline of energy intensity because in a situation of faster economic growth, inefficient technologies can be replaced faster by more efficient ones. Also, at faster economic growth, the structure of the energy system and patterns of energy services change faster, which has the same effect on primary-energy intensity (Roehrl and Riahi, 2000).

The relationship between energy intensity and GDP per capita has been quite regular in the past. It is therefore instructive to present projections of global energy

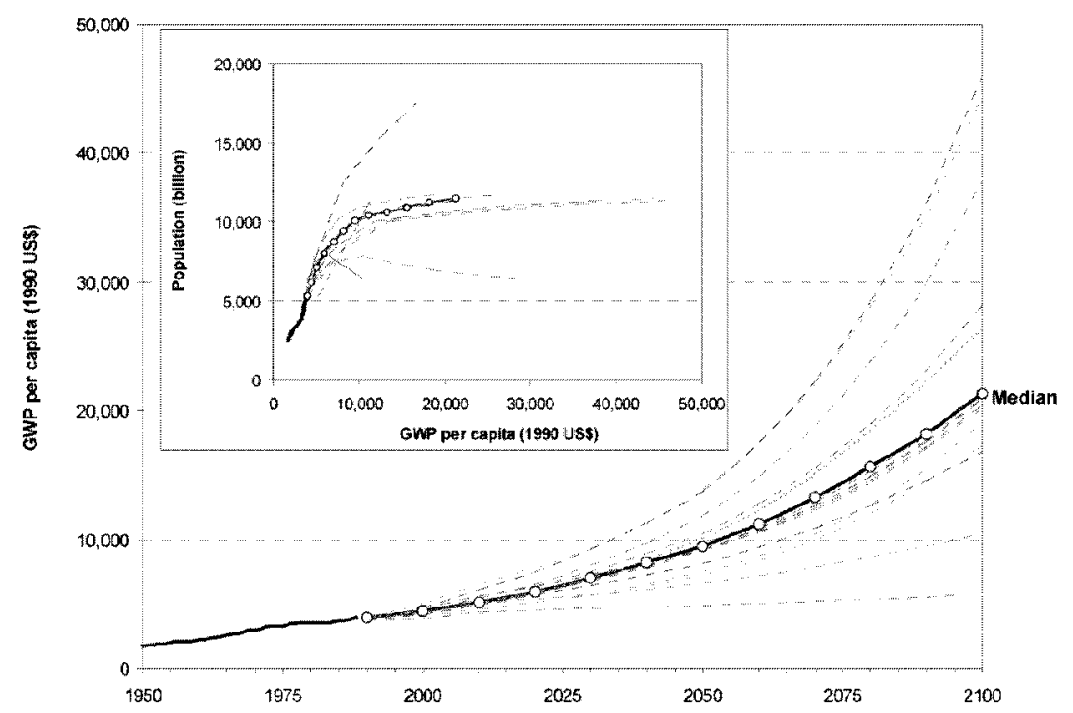

Figure 2: Global gross domestic product (GDP) per capita, development from 1950 to 1990 and in 28 scenarios from the SRES database from 1990 to 2100 . The insert shows global population versus GDP per capita. The gray lines in the insert depict the SRES database scenarios, the green lines show the IIASA sustainable development scenarios, and the blue lines show other IIASA scenarios. Historical data: UN, 1950 through 1995; Database: Morita and Lee, 1998. 
a)

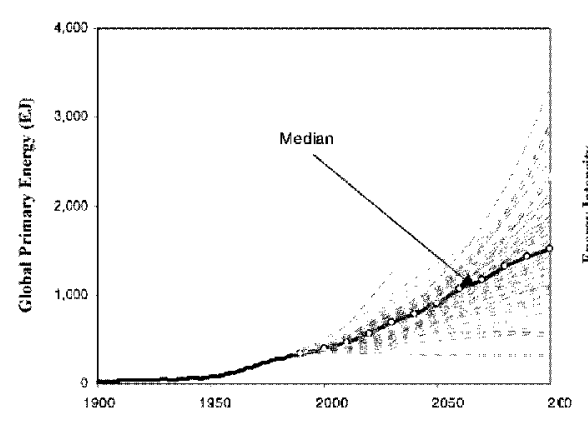

b)

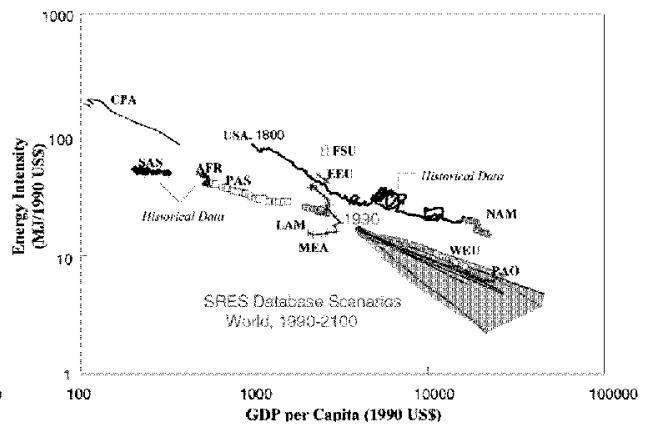

Figure 3: (a) Global primary energy consumption, development from 1900 to 1990 and in 193 SRES database scenarios (from 1990 to 2100). Historical data: Morita and Lee, 1998; Database: Morita and Lee, 1998. (b) Primary energy and GDP per capita, world-regional actual developments (1971 to 1990), USA (1800 to 1990), and in global database scenarios; energy intensity in megajoules (MJ) per US dollar at 1990 prices and per capita in US dollars. Abbreviations: AFR, Sub-Saharan Africa; CPA, Centrally Planned Asia and China; EEU, Eastern Europe; FSU, Former Soviet

Union; LAM, Latin America and the Caribbean; MEA, Middle East and North Africa; NAM, North America; PAO, Pacific OECD; PAS, Other Pacific Asia; SAS, South Asia; WEU, Western Europe. Data sources: IEA, 1993; World Bank, 1993; Morita and Lee, 1998; Nakićenović et al., 1998.

intensity as a function of GDP per capita (Figure 3b). Energy intensity improvement rates from the database range from 0.4 to 1.8 percent per year between 1990 and 2100 , with a median value of 0.8 percent per year, which is in good agreement with the longterm historical rate.

\subsection{Carbon emissions}

The range of projected $\mathrm{CO}_{2}$ emissions across all SRES database scenarios is indeed large, ranging, in 2100 , from ten times the current emissions all the way to negative net emissions (i.e., a preponderance of carbon sinks, assumed in some scenarios). Figure 4 shows the global $\mathrm{CO}_{2}$ emission paths from 1990 to 2100 for the scenarios and the actual emissions from 1900 to 1990 . Global $\mathrm{CO}_{2}$ emissions have increased at an average annual rate of about 1.7 percent since 1900. If this trend would continue, global emissions would double by the year 2030. The median global emissions just exceed 15 gigatonnes of carbon (GtC) in 2100 (a three-fold increase relative to 1990), which can be expected to lead to atmospheric $\mathrm{CO}_{2}$ concentrations of approximately 750 parts per million by volume (ppmv) by $2100.3^{3} \mathrm{~A}$ number of scenarios in the low range are consistent with stabilizing concentrations at levels of $450 \mathrm{ppmv}$.

3 We used the cumulative carbon emissions of the scenarios as a proxy for the estimation of the atmospheric carbon concentrations. 


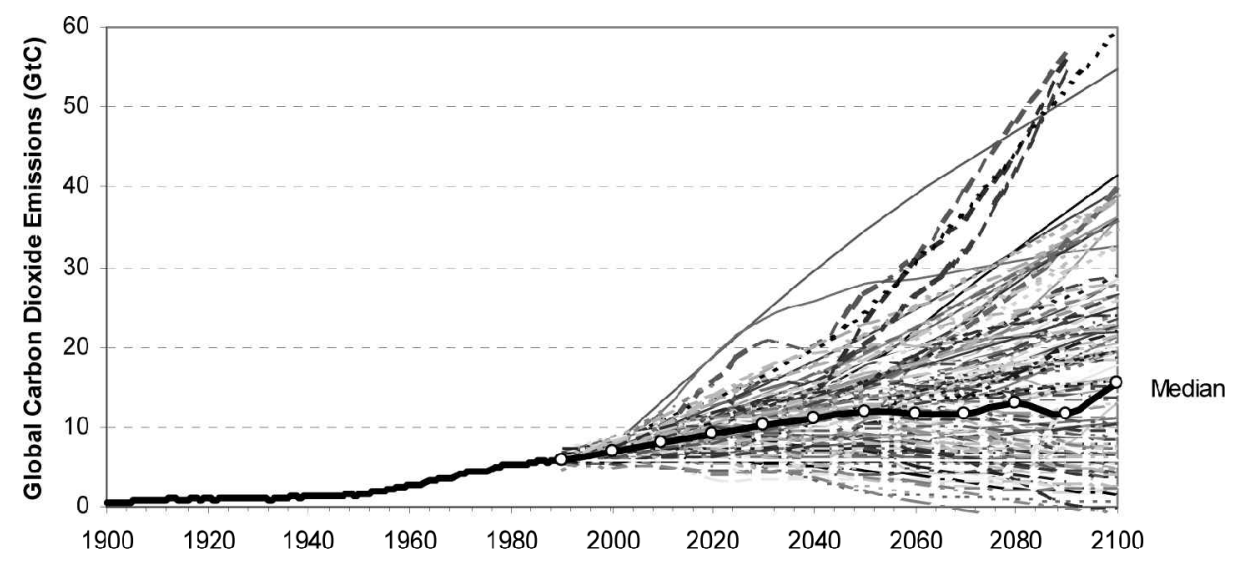

Figure 4: Global carbon dioxide emissions, actual development from 1900 to 1990 and in 256 SRES database scenarios (from 1990 to 2100). Historical data: Marland, 1994; Database: Morita and Lee, 1998.

\subsection{All driving forces together}

A particularly suggestive way of summarising ranges of variables is by drawing percentiles of the samples together with their minimum and maximum values in a polygon. We use this form of presentation in Figure 5, which shows $\mathrm{CO}_{2}$ emissions as well as six other indicators related to the four main driving forces: population, world GDP (absolute level and growth rate), primary energy consumption (absolute level and energy intensity), and carbon intensity of energy. Note that the iso-percentile lines do not necessarily connect values of one and the same scenario. The graphics should therefore be understood as a way of classifying a sample of scenarios and not as a characterization of typical scenarios because the latter ignores the logical connections between the variables.

The range for population projections is the smallest (about three in 2100) among the database scenarios. In contrast, the ranges for both GDP and primary energy consumption vary by a factor of 10 by 2100 . Carbon intensity of energy portrays the highest variation by 2100 compared to other major scenario characteristics in Figure 5 . It varies by nearly two orders of magnitude by 2100 . Thus, it multiplies the differences across primary energy consumption by 2100 by a large factor across the scenarios leading to the enormous span of future $\mathrm{CO}_{2}$ emissions.

\section{WHAT IS SUSTAINABLE DEVELOPMENT?}

Despite a strong consensus on the importance of sustainable development a generally accepted definition remains to be a controversial issue. The notion of sustainable development was introduced to a wider public in 1987 by the report from the World Commission on Environment and Development, which is also known as the Brundtland Report. That report defined sustainable development (SD) as one that 


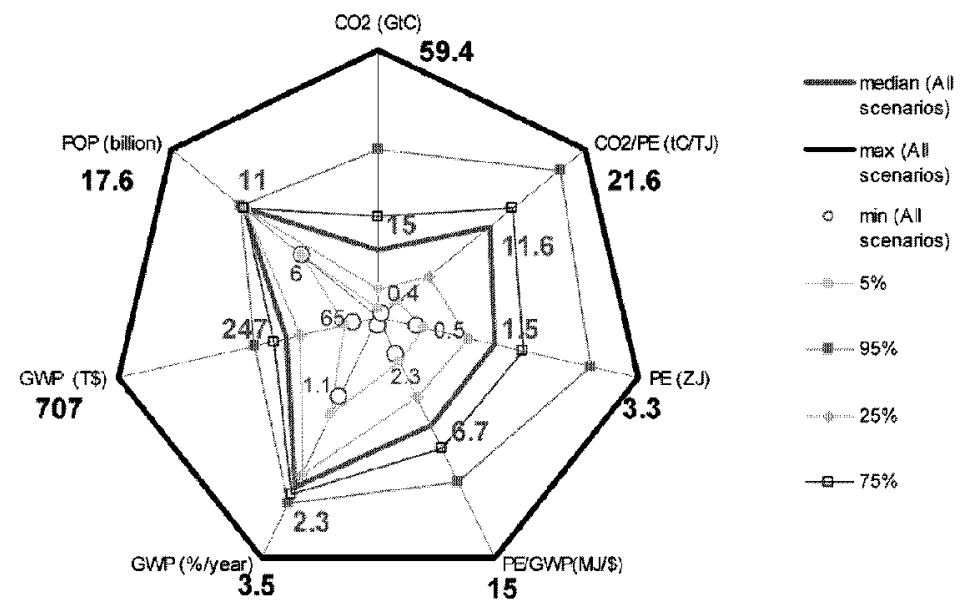

Figure 5: Global carbon emissions from the SRES database and their main driving forces. The minimum, maximum, median and percentile values are shown on seven axes of the heptagon and connected. The axes show the ranges across the scenarios in 2100 of $\mathrm{CO}_{2}$ emissions in $\mathrm{GtC}$, population in billions, gross world product in trillion

US dollars at 1990 prices, gross world product growth rates in percent per year, energy intensity in MJ per US dollar at 1990 prices, primary energy use in zetajoules $\left(\mathrm{ZJ}-10^{21} \mathrm{Joule}\right)$ and carbon intensity in tonne of carbon (tC) per terajoule (TJ).

meets the needs of the present without compromising the ability of future generations to meet their own needs (WCED, 1987). This definition has been widely accepted as the least controversial definition, but it is still much more a strategic goal than a concrete guideline for any practical application. It is therefore not surprising that many authors have come up with different definitions in attempts to find a more policyoriented definition.

One literature survey (Morita and Kawashima, 1993) produced 41 different definitions of sustainable development, while another (Pezzey, 1992) found 61. The issues covered by the various definitions include preservation of biodiversity, environmental carrying capacity, preservation of natural resources, balance between economic activity and environment, sustained economic growth, intergenerational equity, interregional equity, quality of life, as well as social and cultural values (Morita and Kawashima 1993). In our view, which we think is consistent with both surveys, each of these emphasises one of the following three aspects, depending on what is to be sustained.

The first aspect underscores the sustainability of the economic benefit from natural assets. The rationale behind this idea contends that the economic benefit of natural assets should be preserved because it should be shared between the current and future generations. This idea upholds the possibility of a substitution between man-made assets and natural assets. A typical argument along this line can be found in El Serafy (1989), who states that not all revenues from selling natural resources should be 
treated as current income that is available for consumption.

The second aspect emphasises the maintenance of the physical property of the environment. This view puts an absolute value on the preservation of the ecological function of the environment, and the level of the preservation is given in terms of scientific knowledge on ecological property of natural assets.

The third aspect emphasizes non-declining utility, which includes quality of life in the widest sense, and man-made assets in the narrowest sense. This may come on top of sustained economic benefit or sustained physical environment. This is where different values of different people come in, and this sometimes leads to the inclusion of interregional equity, reduction of poverty, human capital or historical monuments in the definition of SD.

Many authors felt that the concept of sustainable development should be translated into a more concrete quantitative definition so as to make this concept operational for policy making. Many of the existing attempts aim at defining some kind of sustainability indicator. Hicks (1946) provided a basis for the economic analysis of sustainable development by defining sustainable income as the maximum value that a country can consume during a period without becoming worse off at the end of the period. However, the Hicksian income concept is fuzzy regarding whether or not it means to keep wealth intact. The definition might mean maintaining its original physical properties or maintaining its value (Peskin, 1998). This disagreement led to the distinction between strong and weak sustainability, the former referring to maintenance of the physical property, the latter to the maintenance of its value (United Nations, 1993a). The strong version of the concept is considered to be extreme, since it prioritises the ecological value to the other values that a human being may have. This observation gave rise to an intermediate view of sustainability, which retains the focus of the weak sustainability definition on preserving the value (rather than a physical condition of the environment), but emphasises preserving the value of natural (instead of total) assets, thus not permitting substitution between natural and man-made assets (Tietenberg, 2000) ${ }^{4}$.

Another well-known starting point for the quantification of sustainable development is a discipline that deals with the analysis of the utility function based on conventional neo-classical economic theory. Variables such as inter-regional equity (Pezzey, 1992) and quality of environmental media (Mäler, 1991; Hamilton, 1996) all fit into the analysis of whether they ensure non-declining utility, i.e., inter-generation equity. All these quantifiable variables are used as proxies of components in the utility function.

Many contributions to the quantification of the sustainability concept follow a procedure that first sets the objective (what is to be sustained) and then establishes a unit that will produce an indicator of sustainability. One of the popular units is simply monetary, and the study of this indicator has developed as Environmental Economics progresses, and different methods of valuing the environment have been experimented with. However, it is still obvious that none of the attempts to define sustainable development in quantitative terms have received a broad acceptance. The major reason for this failure comes from the fact that such attempts focus on establishing sustainable development as a single-dimensional objective.

4 Tietenberg refers to this concept as strong sustainability. 
For the purposes of this paper, quantitative criteria that permit a classification of existing scenarios as sustainable or non-sustainable were needed. We chose a multiplecriteria approach, which is likely to be less controversial than a single-dimensional criterion, and thus propose the following:

Working definition: All scenarios that satisfy the following four criteria are termed sustainable-development scenarios:

(1) Economic growth (GDP per capita) sustains throughout the whole time horizon.

(2) Socio-economic inequity among regions is reduced significantly over the $21 \mathrm{st}$ century, in the sense that by 2100 , the per-capita income ratios between all world regions are reduced to ratios close to those prevailing between OECD countries today (interregional equity).

(3) The reserves-to-production $(\mathrm{R} / \mathrm{P})$ ratios of exhaustible primary energy carriers do not decrease substantially from today's values (intergenerational equity).

(4) Long-term environmental stress is mitigated successfully. In particular, carbon emissions at the end of the 21 st century are near or below today's emissions level. Other GHG emissions may rise, but total radiative forcing (due to all direct or non-direct GHGs) should be on a path to stabilization on the very long-term (on the order of 100 years). Short- to medium-term environmental stress (e.g., acidification) is reduced towards meeting critical.

The advantage of having a multi-criteria approach is its flexibility with respect to emphasizing one view or the other. Although here the selection of the criteria for the working definition was primarily guided by the applicability to the model variables (either parameter or outputs of the models), the possibility of applying different criteria to define a sustainable development scenario was left open.

\section{SUSTAINABLE-DEVELOPMENT SCENARIOS}

The SRES database does not include sufficiently detailed information to allow the evaluation of its scenarios by our four sustainability criteria. In this section, we therefore restrict our analysis to a set of 34 IIASA scenarios. ${ }^{5}$ The IIASA scenarios include those developed together with the World Energy Council (WEC, Nakicenović et al., 1998), and scenarios developed for the IPCC Special Report on Emissions Scenarios (SRES, Nakićenović et al., 2000), as well as scenarios developed for the IPCC Third Assessment Report (TAR). Although we focus our description on sustainable-development scenarios, we sometimes use other scenarios in particular other, non-SD IIASA scenarios for comparison. We distinguish three subgroups:

- $\quad$ seven sustainable-development scenarios according to our working definition.

- $\quad$ eight non-sustainable, non-intervention scenarios; ${ }^{6}$

- $\quad$ nineteen GHG mitigation scenarios. In these scenarios, global atmospheric $\mathrm{CO}_{2}$ concentrations are stabilized at various levels (Riahi and Roehrl 2000a).

5 For a description of the IIASA modeling framework and the data sets used to develop the 34 IIASA scenarios see Riahi and Roehrl (2000a,b).

6 As non-intervention scenarios we refer to scenarios that depict future developments in which no climaterelated policies are assumed to be implemented. As a consequence, these scenarios generally tend to describe future worlds with high GHG emissions. 
It seems worth noting that the main driving variables in this group of IIASA scenarios cover the entire ranges or at least a major part of them generated by all SRES database scenarios. This section first analyses the characteristics of the IIASA sustainable-development scenarios, in particular elaborating on those dynamics in the SD scenarios that lead to closing the North-South income gap (economic catch-up). Next, ranges for SD scenarios with respect to primary energy intensity improvement are shown. In particular, the depletion of (exhaustible) energy resources, such as gas, oil and coal are analysed. Finally, emissions ranges for SD scenarios and key technologies to accomplish sustainable development are presented.

\subsection{Sustainable demographic and economic growth}

Figure 6 shows ranges for global population (left side) and GDP per capita growth (right side) of the SRES database scenarios compared to the range of the 34 IIASA scenarios. The 34 IIASA scenarios cover most of the range of population projections by all database scenarios. Looking at SD scenarios only, we find that their highest population growth (11.7 billion in 2100$)$ is roughly the same as the median from all the scenarios in the SRES database. The entire range of population projections in SD scenarios is clearly in the lower part of the other scenarios. From this observation we conclude that slow population growth at or below median levels is a characteristic of sustainable development.

a)

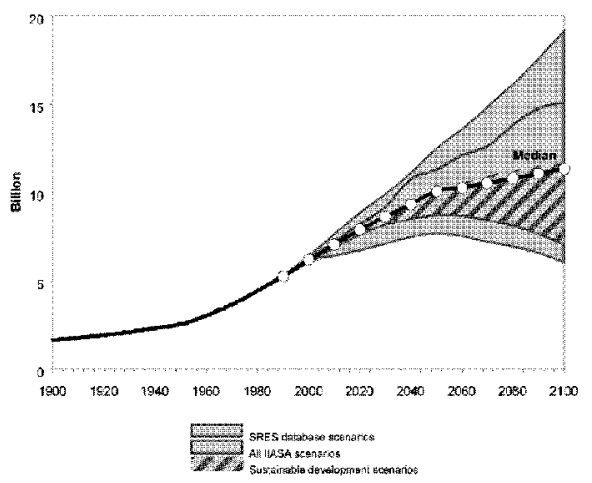

b)

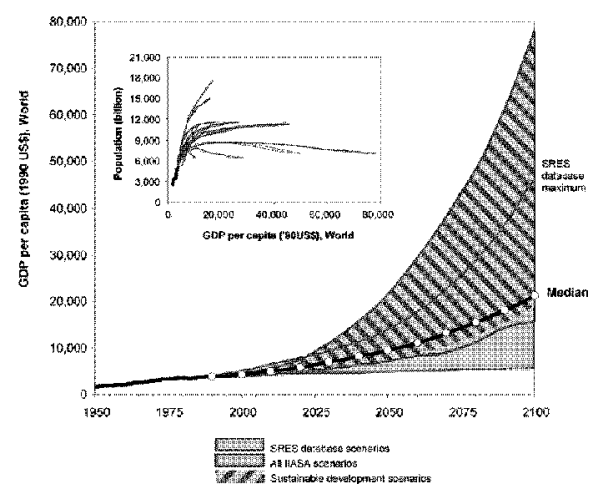

Figure 6: (a) Global population, development from 1900 to 1990 and projections by the SRES database scenarios (from 1990 to 2100). Source of historical data: Durand,

1967; Demeny, 1990; UN, 1996; Database: Morita and Lee, 1998. (b) Global economic product (GDP) per capita, development from 1950 to 1990 and in the database scenarios (from 1990 to 2100). The insert shows global population versus GDP per capita. The grey lines in the insert depict the database scenarios, the green lines show the IIASA sustainable-development scenarios, and the blue lines show other IIASA scenarios. Historical data: UN, 1993b and 1993c; Database: Morita and 
Economic development is a fundamental prerequisite for the eradication of poverty in the world. As shown in the Figure 6b, the 34 IIASA scenarios cover almost the whole range of GDP per capita projections of all SRES database scenarios (excluding a few but noticeable outliers on both ends). The range for the SD scenarios is practically identical to the range for all IIASA scenarios. This illustrates that future GDP levels per se are less critical for a sustainable future pathway than the income distribution among regions.

The decreasing income differences between the world regions in the IIASA SD scenarios are illustrated in Figure 7. The reduction in inequity may be measured as the ratio of GDP per capita between today's developing countries and the OECD. At present, this ratio is approximately six percent, compared to the long-term ratios in the IIASA scenarios, which range from 21 to 64 percent in 2100 .

The insert in Figure $6 \mathrm{~b}$ illustrates some of the relationships between population and GDP per capita in the scenarios. Generally, higher GDP per capita goes along with lower global population projections. In all SD scenarios, global population transition is achieved during the next century and stabilization occurs at population levels of around (or below) 11 billion people. Generally, this is associated with relatively high levels of economic development in the range from US $\$ 20,000$ to US $\$ 80,000$ per capita.

\subsection{Sustainable resource consumption and energy use}

To be effective, sustainable-development strategies must, in addition to mitigating the negative consequences of energy, also reduce primary energy use per unit of GDP. Consequently, energy intensity reduction is particularly steep in the SD scenarios

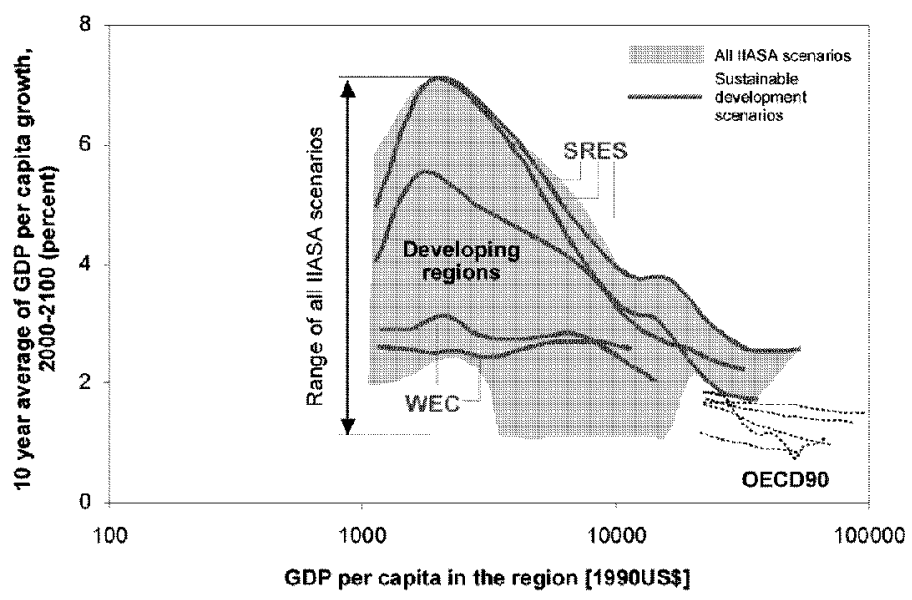

Figure 7: Developing regions catch-up in the IIASA (WEC and IPCC SRES) scenarios, expressed in terms of annual GDP per capita growth (10-year average) at a given GDP per capita. 
(Figure 8). The range for the SRES database scenarios is almost equal to the range spanned by the 34 IIASA scenarios ( 0.7 to 1.8 percent per year). The median improvement rate in the SRES database is about one percent per year, corresponding to the long-term historical trend, and all SD scenarios are at or below the median.

It is often argued that oil, gas and coal are utilized in a non-sustainable way. During the 1970 s and 1980s in particular, it was frequently feared that the world could quickly run out of fossil energy. The long-term historical evidence, however, suggests that the situation is less drastic than feared, mainly due to the common failure to appreciate the difference between reserves and resources (see, e.g., Rogner, 1997). Since reserves are defined as only that part of the resources that it is technically and economically feasible to extract, these amounts are a function of the available technologies and market conditions at a given point in time. Hence, for the IIASA runs, the assumed quantities of reserves depend strongly on the assumptions of the then techno-economic situation assumed to prevail in a scenario.

The preceding discussion was the motivation for us to include the reserve-toproduction $(\mathrm{R} / \mathrm{P})$ in our working definition of sustainable development. As a consequence of technological progress and changing market conditions, this ratio has most notably for crude oil and natural gas recently remained fairly constant on the global level (BP Amoco, 1999). The long-term development of R/P ratios (for gas and oil for the year 2100) for the SD scenarios from SRES are illustrated in Table 1.

\section{Table 1: Reserve-to-production-ratios and global production of natural gas and oil in sustainable-development scenarios}

\begin{tabular}{ccccc} 
& \multicolumn{2}{c}{ Natural gas } & \multicolumn{2}{c}{ Oil } \\
\cline { 2 - 5 } & $\begin{array}{c}\text { Global } \\
\text { production } \\
\text { (EJ/yr) }\end{array}$ & $\begin{array}{c}\text { R/P ratio } \\
\text { (years) }\end{array}$ & $\begin{array}{c}\text { Global } \\
\text { production } \\
\text { (EJ/yr) }\end{array}$ & $\begin{array}{c}\text { R/P ratio } \\
\text { (years) }\end{array}$ \\
\hline SD scenario estimates for 2100* & & & & \\
SRES-A1T & 196 & 127 & 77 & 178 \\
SRES-B1 & 215 & 49 & 45 & 55 \\
SRES-B1G & 244 & 40 & 53 & 44 \\
SRES-B1T & 166 & 81 & 48 & 54 \\
1990 value & 72 & 58 & 139 & 43 \\
\end{tabular}

*Note that the R/P ratios for the three WEC SD scenarios are not available.

The biggest decline of $\mathrm{R} / \mathrm{P}$ ratios in Table 1 is reported for the SRES-B1G scenario, in which the R/P ratio for gas drops from 58 years in 1990 to 40 years in 2100. Table 1 also shows the relative abundance of natural gas compared to oil in the SD scenarios in the 21 st century. This abundance is based mainly on the assumption of rapid technological progress that will allow the extraction of vast amounts of nonconventional gas in a cost- effective way (Rogner, 1997). 


\subsection{Carbon emissions and key technologies in SD scenarios}

The range of carbon emissions projections by the IIASA scenarios in 2100 ( $2.3 \mathrm{GtC}$ to $32.7 \mathrm{GtC}$ ) covers the emission trajectories of more than 95 percent of all scenarios from the SRES database (Figure 9). Only a few outliers of the database fall outside the

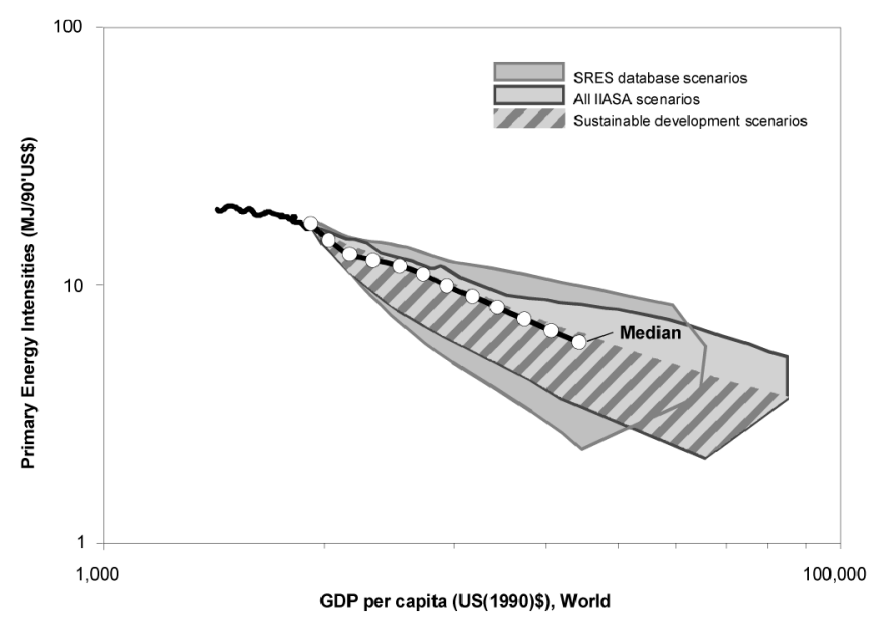

Figure 8: Global primary energy intensity in relation to GDP per capita, development from 1960 to 1990 and in the database and IIASA scenarios (from 1990 to 2100). Historical data: IEA, 1993; World Bank, 1993. Database: Morita and Lee, 1998.

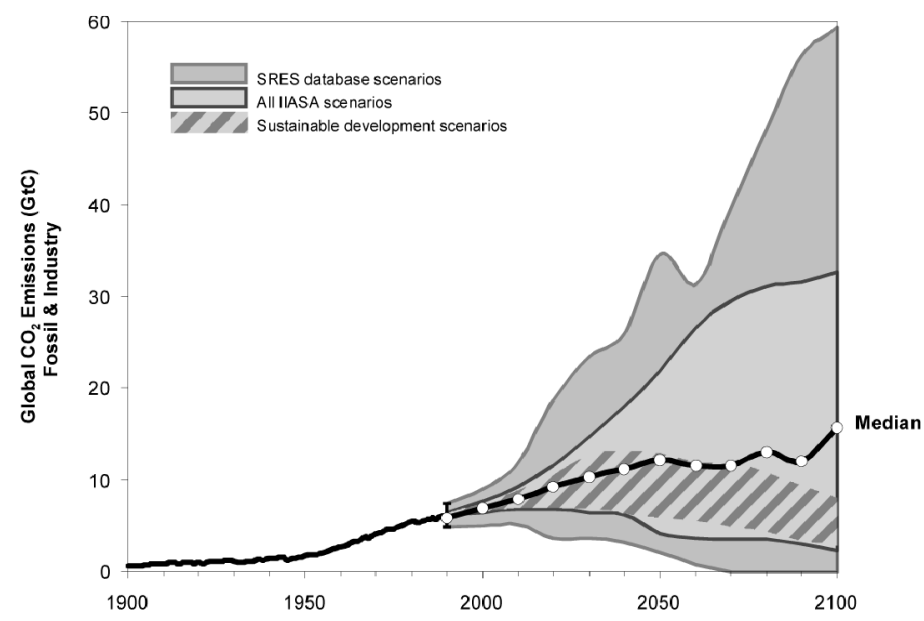

Figure 9: Global carbon dioxide emissions, actual development from 1900 to 1990 and in the scenarios (140 of which from the SRES database) from 1990 to 2100.

Historical data: Marland et al., 1994; Database: Morita and Lee, 1998. 
projections by IIASA scenarios. Among the IIASA scenarios, carbon emissions are of course lowest for SD scenarios and mitigation scenarios, which aim to stabilize atmospheric concentrations at 450 ppmv by 2100 .

Carbon emissions projected by SD scenarios range from $2.9 \mathrm{GtC}$ to $8 \mathrm{GtC}$ in 2100 . This corresponds to carbon intensities of primary energy that decline much faster (one to two percent per year) than the historical trend of 0.3 percent per year (Nakicenovic et al., 1993). This overall tendency towards significantly lower carbon intensities can only be achieved by the rapid and continuous replacement of carbon-intensive technologies with new, advanced and particularly cleaner ones. But which are the most promising technologies in the energy sector that can accomplish an efficient transition from the present energy system to sustainability?

This question was addressed by Riahi et al. (2001), who use the same IIASA scenarios as described here to identify key technologies of the global power sector. In that analysis, solar photovoltaic and hydrogen fuel cell technologies were identified as the most promising long-run options to pursue sustainable development. There is also a strong agreement across all SD scenarios that natural-gas technologies, in particular fuel cells and the combined cycle, could accomplish a smooth and efficient transition to eventual sustainability.

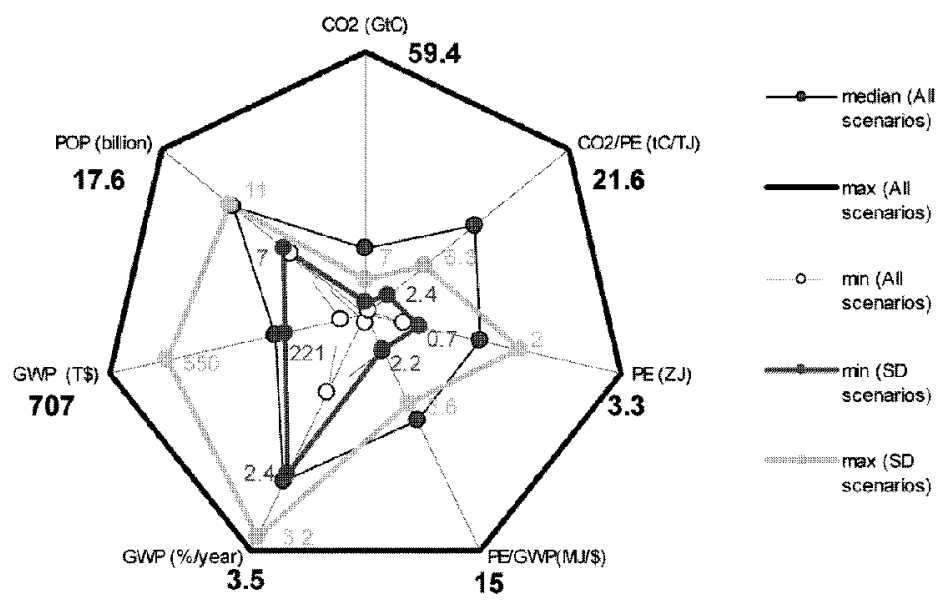

Figure 10: Global carbon emissions and their main driving forces. The minimum and maximum, values for the SRES database and the SD scenarios are shown on seven axes of the heptagon and connected. The seven axes show the ranges across the scenarios in 2100 of $\mathrm{CO}_{2}$ emissions in $\mathrm{GtC}$, population in billions, gross world product in trillion US dollars at 1990 prices, gross world product growth rates in percent per year, energy intensity in MJ per US dollar at 1990 prices, primary energy in $\mathrm{ZJ}\left(10^{21}\right.$ Joule) and carbon intensity in $\mathrm{tC}$ per $\mathrm{TJ}$. 


\subsection{Conclusions for SD scenarios}

The ranges of scenario indicators for SD scenarios compared to the SRES database ranges are summarised in Figure 10. The figure shows carbon dioxide emissions as well as six other indicators related to the four main driving forces: population, world GDP (absolute level and growth rate), primary energy consumption (absolute level and energy intensity), and carbon intensity of energy.

The main findings of the assessment of SD scenarios are that:

- Slow population growth respectively stabilization of global population appears to be a prerequisite for sustainable development.

- Following the "working definition" of sustainability, global future economic growth alone does not guarantee a sustainable future. More important in this respect is whether the economic and environmental inequity (gap) among regions is reduced or not.

- In a sustainable future, energy intensity must improve at least as fast as the historic trend (one percent per year), and carbon intensities must decrease much faster than the historic trend ( 0.3 percent per year).

- To achieve sustainable development, strategies for fossil resource consumption must aim at non- decreasing reserve-to-production $(\mathrm{R} / \mathrm{P})$ ratios by making sure that technological progress keeps converting sub-economic resources into economically recoverable reserves as long as fossil fuels are produced.

- Carbon emissions may increase in the short run, but have to be near or below today's level at the end of this century.

- Consistently high market shares of solar photovoltaic and hydrogen fuel cell technologies in SD scenarios suggest that these technologies could be the most promising long-run options to pursue sustainable development. Natural-gas technologies, in particular fuel cells and the combined cycle, could accomplish a smooth and efficient transition to eventual sustainability.

\section{TOWARDS AN EFFECTIVE POLICY FOR TECHNOLOGICAL PROGRESS}

The previous sections have shown how long-term energy-economy-environmental (E3) scenarios can be analysed to determine which technology clusters are likely to have a high market share in a sustainable future. The question now becomes which policies can promote these technologies. We begin by summarising the concept of technological learning and its consequences for policy making. In a nutshell, technological learning as used here describes regular technological progress, expressed as specific technology cost, as a function of cumulative installed capacity of the technology in question. Following this simple concept, policies could support technological progress by promoting its diffusion. The main examples for such policies are subsidizing the technologies market price or by direct procurement. In this simple model, it appears somewhat unsatisfactory that technological progress cannot be enhanced more directly, such as by allocating resources to R\&D. To heed this shortcoming, a modified, two-factor learning curve has been developed, in which $R \& D$ expenditures are added as a second factor (in addition to cumulative capacity) enhancing technological progress. Policies based on such a concept would deploy the obvious instrument of supporting R\&D of energy technologies. 


\subsection{Learning-by-doing and procurement}

The well-known concept of learning curves is based on the observation that cost improvements for many energy technologies are better explained as functions of cumulative experience than as functions of time. A learning curve postulates that the unit production cost of a manufactured item decreases with the cumulative production of that item. In a more general formulation of the concept, any performance indicator can play the role of production costs, and other experience indicators can be used in lieu of cumulative production. For energy technologies, the most common way to express technological learning is to postulate a constant relative reduction of technology costs for each doubling of total installed capacity. With this definition, a learning rate of 20 percent means that capital costs per unit of newly installed capacity of a given technology decreases by 20 percent for each doubling of total installed capacity.

A systematic collection and estimation of learning curves and learning rates for energy technologies was initiated at IIASA in 1999. The catalogue of learning rates comprises 42 energy technologies. The distribution of all 42 learning rates is shown in Figure 11. Learning rates vary between 14 and 42 percent with a low peak around 2 to 6 percent and a high peak around 18 percent.

The overall pattern shown in the figure is quite irregular. The distribution has holes that cannot be plausibly explained and three apparent modes. One possible reason is that our sample size is still too small and that as more learning rate estimates are added to the distribution, it will become more regular. Another reason could be that in those cases where we could not estimate learning rates ourselves, different methods or conventions were used. With the exception of the 10 percent hole, the distribution of these learning rates is very similar to the survey of learning rates in the whole manufacturing sector as published by Dutton and Thomas (1984).

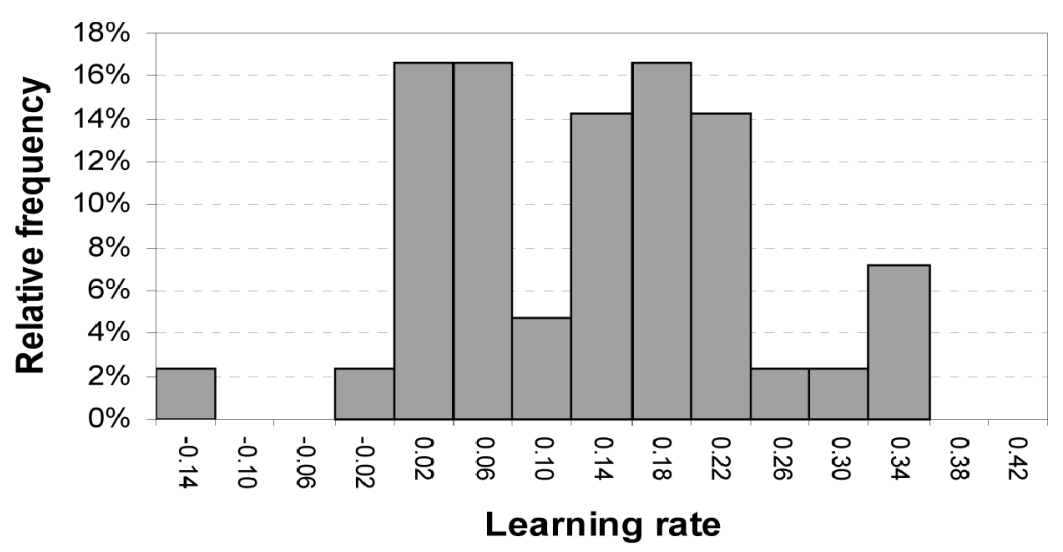

Figure 11: Learning rates of 42 energy technologies. Source: McDonald and

Schrattenholzer, 2001. 
A typical situation in which technological learning of an energy technology is relevant, is the case of a learning technology, which is not competitive at a given point in time, but can be expected to be competitive as learning keeps progressing at a given rate. In such a situation, higher costs in the near term would be compensated by cost savings later, but since the costs and benefits would not incur to the same economic agents, public policy is called upon to balance this asymmetry by carrying the extra costs by subsidies by procurement programmes, or through technical mandates.

One such programme in support of a learning technology is the well-known Japanese Sunshine project, which helps finance the installation of solar photovoltaic (PV) rooftop systems. Technological progress in the manufacturing of solar photovoltaic modules has been studied extensively not only to estimate pure learning effects, but also to assess the effectiveness of private and public R\&D expenditures (Watanabe and Griffy-Brown, 1999).

The learning concept has also been used in formulating a new German law (Erneuerbare-Energien-Gesetz) on renewable energy. The new law requires utilities to buy electricity from renewable energy at a certain minimum rate. These guaranteed rates are technology-specific and are reduced every year. For solar PV, the reduction is 5 percent per year from an initial level of 0.505 Euro per kilowatt-hour $(\mathrm{kWh})$. In addition, for PV the law set up a checkpoint at a cumulative capacity of 350 megawatt (MW). At this level, the German Parliament will need to make a new decision on a guaranteed rate for $\mathrm{PV}$, taking into consideration the cost reduction that has been achieved since the law was enacted. In other words, the law will be amended in a way that depends on how well technological progress, in the field of PV, will follow the past learning curve.

The concept of technological learning can also be used to analyse the impacts of subsidy schemes on cost-reductions. We examined the impact of (procurement) subsidies and R\&D support on cost of wind energy in three countries. In Denmark, R\&D support and other instruments (investment subsidies and fiscal incentives) have been used to promote wind energy. From the mid-1980s, the subsidy consisted of a guaranteed tariff paid by the energy supply companies to wind farm operators. In addition, the government subsidised wind electricity production from the levied energy and environmental taxes. In Germany, the major government instruments were the 100/250MW programmes, the feed-in law, tax breaks, as well as, the provision of low-interest loans. The feed-in law requires public energy supply companies to pay wind turbine operators at least 90 percent of the average electricity price normally paid to consumers. In the United Kingdom (UK), R\&D efforts were complemented by a guaranteed premium price per $\mathrm{kWh}$ generated. A typical element of the UK system is that the contracts awarded and the price paid for the wind electricity generation result from a repeated process of competitive bidding within a (renewable energy) technology band.

When estimating the one-factor learning with cumulative subsidies as the only factor, we find that investment costs are highly correlated with the cumulative subsidies in all three countries analysed. It appears that subsidies led to the steepest investment cost reduction in the UK, followed by Denmark and Germany (see Figure 12). In our view, this sharp reduction was related to the competitive nature of the bidding procedure for subsidies in the UK. 


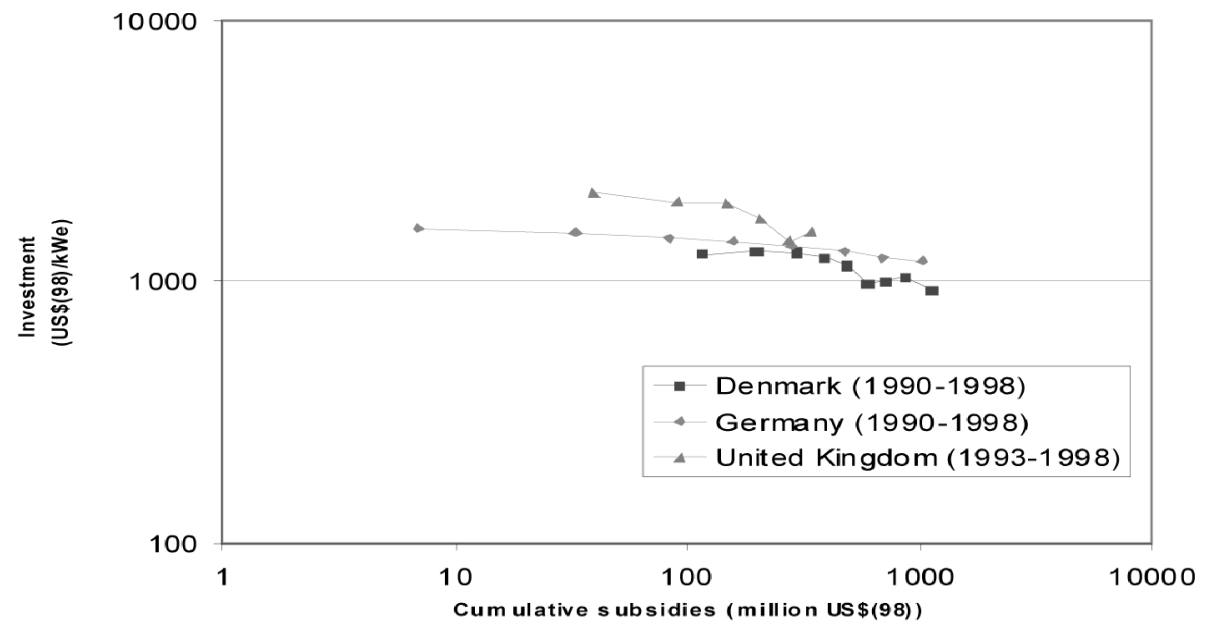

Figure 12: Investment costs and cumulative subsidies for wind farms in Denmark, Germany and the UK, displayed in a learning-curve format.

\subsection{Two-factor learning curves}

Following the positive results of more aggregated studies of R\&D effectiveness (Griliches, 1975 and 1998; Nordhaus, 1999; Watanabe, 2000), Kouvaritakis et al. (2000) presented the concept of the two-factor learning curves of energy technologies. In this concept, cumulative expenditures on research and development of energy technologies are added as a second factor explaining cost reductions. Several problems and open questions still exist in connection with this extended concept, but we think that first general conclusions can be drawn in a way that does not depend on the resolution of all open issues.

To arrive at these conclusions we have used a modified version of the Energy Research and Investment Strategy (ERIS) model developed by Barreto and Kypreos (2000). In the version used for the analysis presented here, ERIS describes the global electricity generation sector during the 21 st century. ERIS is an optimisation model that minimizes the total costs, including R\&D expenditures, of generating a given trajectory of electricity demand. The effect of R\&D expenditures on costs is captured by a so-called two-factor learning curve (2FLC). A 2 FLC follows the same concept as conventional (one-factor) learning curves, just adding R\&D expenditures as a second factor (in addition to cumulative capacity) enhancing technological progress. The single learning rate in conventional learning curves is now replaced by two rates, now referred to as learning-by-doing rate (LDR) and learning-by-searching rate (LSR).

Our analysis addressed the following questions: (1) What are the optimal $R \& D$ levels? This question was of interest because in the real world, constraints on R\&D expenditures appear to be determined by constrained budgets rather than by optimisation. (2) Can the ERIS model describe crowding out situations? By crowding 
out we refer to the often-quoted possibility that investments into R\&D of one technology can exclude the support of another energy technology at the same time. (3) Can the ERIS model describe the lock-in of one learning technology? Lock-in here refers to a situation, in which one technology becomes so cheap that no other new technology is developed. As a concept, lock-in is value-free, but being locked into a bad technology is obviously bad.

We have analysed these questions in a stylised way by choosing two learning technologies, wind and solar PV, and reference values for the two parameters of each 2FLCs that we found to be the most plausible within a given range of estimates (see Table 2). ${ }^{7}$

Table 2: Learning parameters determining two-factor learning curves (2FLCs) for solar PV and wind power

\begin{tabular}{lcc} 
& Solar PV & Wind \\
\hline Learning-by-doing rate (LDR), percent & 17.5 & 10 \\
Learning-by-searching rate (LSR), percent & 10 & 10
\end{tabular}

Using these learning rates, we have made two runs with the ERIS model, each including a 2FLC for one of the two technologies. (The other one and all other technologies were assumed to have constant costs over time.) The resulting optimised R\&D expenditures are shown in Figure 13.

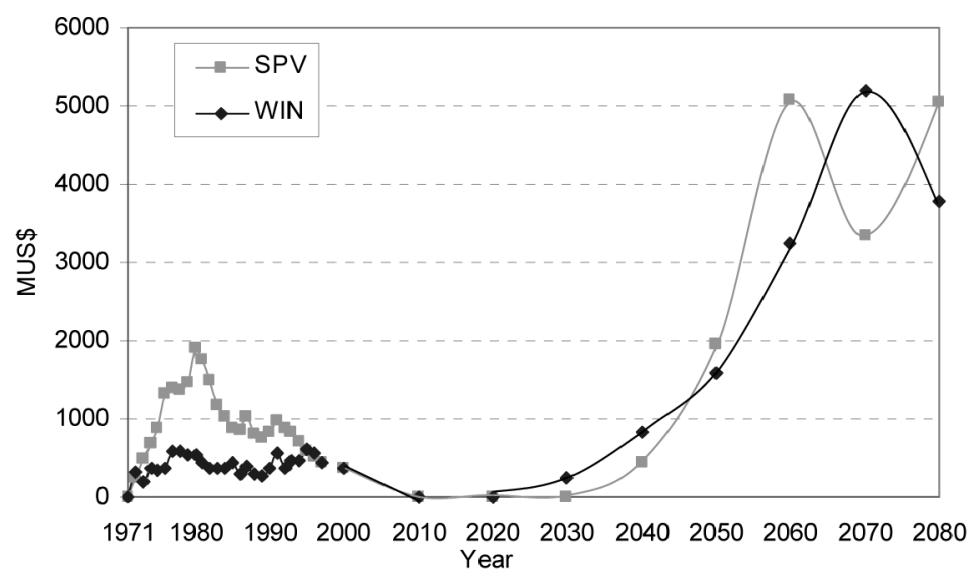

Figure 13: R\&D expenditures for wind and solar PV power generation (Reference

Case), optimised separately by ERIS, and actual past R\&D expenditures.

7 The estimated values of the parameters depend on assumptions such as on initial values. 
The figure suggests that optimised R\&D support begins to exceed today's levels after the year 2050, having declined earlier. The emerging picture suggests that perhaps the time has not come yet for these two renewable energy technologies. In light of the experimental nature of the input numbers used in the analysis and given that no carbon constraints were included, this conclusion can be taken only with a grain of salt at best. More important in our view is the observation that the optimised levels of R\&D are of the same order of magnitude as actual levels of the past in spite of the absence of R\&D budget constraints.

We addressed the questions of lock-in and crowding out with a series of ERIS runs, in which we included 2FLCs for solar PV and wind power generation, varying the learning parameters for both technologies in the neighbourhood of their reference values. The model results, in terms of optimised R\&D levels, are shown in Figure 14.

The main message of the figure is that the two learning technologies, solar PV and wind power, can develop and receive $R \& D$ support at the same time. This remains true over a range of learning rates (LSR and LDR) for the two technologies. Only if we assume particularly high learning-by-doing rates for one of the two renewable technologies (wind power), optimised R\&D support of the other one (PV) is reduced to zero.

In conclusion, we would like to stress again that we have presented here stylised results, which we consider to be mainly of methodological interest. The road to more policy-relevant results leads through improvements of both the empirical basis (data) and refinement of the concept. At the end of our next round of efforts to improve our
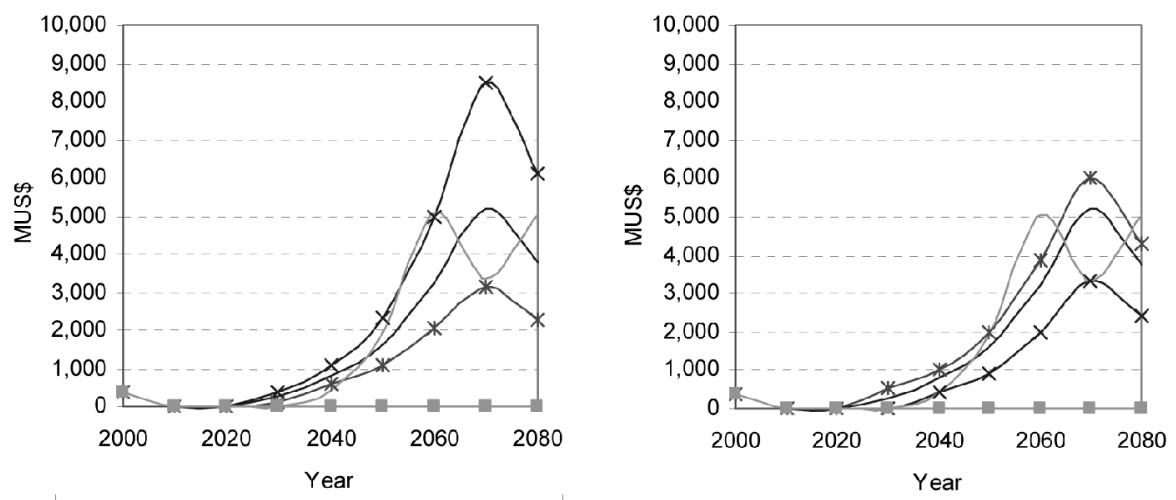

$*$ WIN: (LDR for $W I N=5)$

* WIN: (LDR for $W I N=15)$

WIN: (Reference)

SPV: (Reference), (LDR for WIN=5)

$\rightarrow-S P V:($ LDR for $W I N=15)$

* WN: (LSR for $\mathrm{WIN}=5)$

$\rightarrow-W N$ : (LSR for WIN=15)

- WN: (Reference)

SPV: (Reference), (LSR for WIN=5)

$-\mathrm{SPV}:($ LSR for WIN=15)

Figure 14: Time evolution of optimised R\&D expenditures for wind (WIN) and solar photovoltaic (SPV) energy technology; learning parameters for WIN are fixed at their reference values; LSR fixed for SPV [left] and LDR fixed for SPV [right]. 
analysis along both lines we hope to be able quantify costs and benefits of R\&D spent on energy technologies more reliably.

\section{SUMMARY AND CONCLUSIONS}

The intensity with which the Kyoto Protocol and its possible implementation is discussed could easily distract the international community from the fact that meeting the Kyoto targets is neither necessary nor sufficient to achieve climate stabilization below dangerous levels. In this report, we take it from the not necessary by analysing an existing set of global energy-economy-environmental (E3) scenarios from the point of view of an environmentally compatible development of the global energy system. To do this, we refer to an even more general concept of environmentally conscious strategies sustainable development. We then proceed by identifying energy technologies that in the analysed scenarios play a key role in achieving sustainable development. In conclusion, we describe how policy makers could make use of insights in the dynamics of technological progress to promote the development of promising technologies.

Our overview of the scenario literature considers more than 400 scenarios summarised in the SRES (Special Report on Emissions Scenarios) database. Our analysis focuses on quantifying the ranges of GHG emissions and their main driving forces as projected by the database scenarios. Population projections envision a slowing growth of future global population. The range for population is the smallest (a factor of three in 2100). In contrast, the ranges for GDP and primary energy consumption vary by a factor of 10 by 2100 . Carbon intensity of energy portrays the highest variation by 2100. It varies by nearly two orders of magnitude by 2100 . Together with the differences between primary energy projections, this leads to the enormous span of future $\mathrm{CO}_{2}$ emissions ranging, in 2100, from ten times the current emissions all the way to negative net emissions.

Despite a strong consensus on the importance of sustainable development (SD), the exact definition of the concept remains to be a controversial issue. Existing surveys suggest that at least 40 to 60 definitions exist. For the purpose of analysing the sustainability of the IIASA scenarios, we adopted the following criteria for sustainable development: (1) Economic growth sustains throughout the whole time horizon; (2) socio-economic inequity among world regions is reduced significantly during this century; (3) reserves-to-production $(\mathrm{R} / \mathrm{P})$ ratios of exhaustible primary energy carriers do not decrease substantially from today's values; and (4) short- to medium-term environmental impacts (e.g., acidification) do not exceed critical loads and carbon emissions at the end of the century are close to or below today's levels. We think that this working definition might be a step towards a more generally accepted definition of SD. If it is, their flexible formulation may leave room for several directions to move into.

By applying these criteria to a set of IIASA scenarios we identify SD scenarios and compare their main indicators with the ranges from the SRES database. We conclude that slow population growth leading to at least stabilisation of global population (at median levels) is a prerequisite for sustainable development. Energy intensity must improve at least as fast as the historic trend (one percent per year), and carbon 
intensities must decrease much faster than the historic trend ( 0.3 percent per year). Strategies for fossil resource consumption must aim at non-decreasing reserve-toproduction ratios by making sure that technological progress keeps converting subeconomic resources into economically recoverable reserves as long as fossil fuels are produced. In terms of individual technologies, solar photovoltaic and hydrogen fuel cell technologies appear as the most promising long-run options. Natural-gas technologies, in particular fuel cells and the combined cycle, could accomplish a smooth and efficient transition to eventual sustainability.

The question then becomes which policies can promote the development of these technologies. In our opinion, an important tool to tackle this question is provided by an improved concept of technological learning. According to that concept, technological progress, expressed as specific technology cost, is a regular function of not only cumulative installed capacity but also of R\&D support (two-factor learning curves 2FLCs). This implies that both procurement (which increases capacity) as well as $R \& D$ are important policy tools. With respect to procurement we find that the concept of technological learning rests on a sufficiently sound empirical basis to derive expected costs reductions from expected capacity expansions. We also find that competitive bidding schemes for allocating subsidies might be more effective in reducing costs than fixed subsidies.

Regarding optimal R\&D levels for technologies the technological progress of which is described by 2FLCs, preliminary results of model analyses for two renewable energy technologies (wind and solar PV) suggest that optimised R\&D support comes out to be of the same order of magnitude as actual R\&D expenditures observed in the past. Analysing the familiar concepts of crowding out and lock-in, we also find the two learning technologies can develop and receive R\&D support at the same time. This remains true over a range of learning rates for the two technologies.

We would like to emphasize again that our results based on the use of 2FLCs are stylised as far as policy relevance is concerned, being at this point in time mainly of methodological interest. The road to more policy-relevant results leads through improvements of both the empirical basis (data) and refinement of the concept. At the end of our next round of efforts to improve our analysis along both lines we hope to find quantitative answers on our quest for the optimal allocation of expenditures on both procurement and R\&D over the various energy technologies.

\section{ACKNOWLEDGEMENTS}

Parts of the work reported here were supported by the Central Research Institute of the Electric Power Industry (Japan), the Commission of European Community (Brussels), and the Economic and Social Research Institute of the Cabinet Office (Japan).

\section{REFERENCES}

Barreto, L. and S. Kypreos, 2000, A post-Kyoto analysis with the ERIS model prototype, International Journal of Global Energy Issues 14(14):262-280.

BP (British Petroleum) Amoco, 1999, BP Statistical Review of World Energy 1999, BP, London, UK. 
Demeny, P., 1990, Population, in B.L.Turner II, et al. (ed.), The Earth As Transformed by Human Action, Cambridge, Cambridge University Press.

Durand, J.D. 1967, The modern expansion of world population, Proceedings of the American Philosophical Society, 111(3): 136159.

Dutton, J.M., and Thomas, A., 1984, Treating progress functions as a managerial opportunity, Academy of Management Review, 9(2): 235247.

El Serafy, E., 1989, The Proper Calculation of Income from Depletable Natural Resources. Y. Ahmad, S. El Serafy and E. Lutz eds. Environmental Accounting for Sustainable Development. A UNEP World Bank symposium, The World Bank, Washington D.C.

Griliches, Z., 1975, Returns to Research and Development Expenditures in the Private Sector, in J.W. Kendrick and B.N. Vaccara, eds., New Developments in Productivity Measurement and Analysis, University of Chicago Press, Chicago, IL, USA, pp.419-461 (ISBN 0-226-43080-4).

Griliches, Z., 1998, $R \& D$ and productivity, University of Chicago Press, Chicago/London.

Hamilton, K., 1996, Pollution and Pollution Abatement in the National Accounts. The Review of Income and Wealth. Series 42, No. 1, March, pp. 13-34.

Hicks, J.R., 1946, Value and Capital, Oxford Press.

IEA (International Energy Agency) 1993, Energy Statistic and Balances for OECD and nonOECD countries 19711991, OECD, Paris, France.

Kouvaritakis, N., Soria, A., Isoard, S., 2000, Modelling energy technology dynamics: methodology for adaptive expectations models with learning by doing and learning by searching, International Journal of Global Energy Issues 14(1-4):104-115.

Mäler, K-G., 1991, National Accounts and Environmental Resources. Environmental and Resource Economics. No. 1, pp. 1-15.

Marland, G., R.J. Andres, and T.A. Boden, 1994: Global, regional, and national $\mathrm{CO}_{2}$ emissions. pp.505-584. In Trends 93: A Compendium of Data on Global Change, ORNL/CDIAC-65. T.A. Boden, D.P. Kaiser, R.J. Sepanski, and F.W. Stoss (eds).,Carbon Dioxide Information Analysis Center, Oak Ridge National Laboratory, Oak Ridge, TN, pp. 505-584.

McDonald, A. and Schrattenholzer, L., 2001, Learning curves and technology assessment, Special Issue of the International Journal of Technology Management (in press).

Morita, T., and Lee, H.-C., 1998: IPCC SRES Database, Version 0.1, Emission Scenario Database prepared for the IPCC Special Report on Emission Scenarios, http://wwwcger.nies.go.jp/cger-e/db/ipcc.html.

Morita, T., and Y. Kawashima, 1993, Sustainable development its definitions and goals, Mitatakkai Zassi (Mita Economic Journal) 85(4) (in Japanese).

Nakićenović, N., J. Alcamo, Davis, G., de Vries, B., Fenhann, J., et al., 2000, Special Report on Emissions Scenarios (SRES), A Special Report of Working Group III of the Intergovernmental Panel on Climate Change, Cambridge University Press, Cambridge, UK.

Nakićenović, N., Grübler, A. and McDonald, A., (eds.), 1998, Global Energy Perspectives. Cambridge University Press, Cambridge, UK, ISBN 0521642000. 
Nakićenović, N., Grübler A., Inaba A., Messner S., Nilsson S., et al., 1993, Long-Term Strategies for Mitigating Global Warming, Energy The International Journal, Vol.18(5):401-421.

Nordhaus, W., 1999, Modeling Induced Innovation In Climate-Change Policy, paper presented at the International Workshop on Induced Technological Change and the Environment Workshop, 21-22 June 1999, IIASA, Laxenburg, Austria.

Peskin, H., 1998, Alternative Resource and Environmental Accounting Approaches and their Contribution to Policy. In Uno and Bartelmus (eds.) Environmental Accounting in Theory and Practice. Kluwer Academic Publishers. Dordrecht.

Pezzey, J., 1992, Sustainable development concepts An economic analysis. World Bank Environment Paper Number 2, World Bank, Washington, D.C., US.

Riahi, K. and R.A. Roehrl, 2000a, Energy technology strategies for carbon dioxide mitigation and sustainable development, Environmental Economics and Policy Studies, 3(2):89-123.

Riahi, K. and R.A. Roehrl, 2000b, Greenhouse Gas Emissions in a Dynamics-as-usual Scenario of Economic and Energy Development. Technological Forecasting and Social Change, 63(2-3)175-205.

Riahi, K., Roehrl, R.A., Schrattenholzer, L. and Miketa, A., 2001, Technology Clusters in Sustainable Development Scenarios, Progress Reports of Environmental Issue Groups, International Forum of the Collaboration Projects in Spring 2001, Tokyo.

Roehrl, R.A., and K. Riahi, 2000,: Technology dynamics and greenhouse gas emissions mitigation: A cost assessment, Technological Forecasting \& Social Change, 63(3): 231-261.

Rogner, H.H., 1997: An Assessment of World Hydrocarbon Resources, Annual Review of Energy Environment, 22:217-262

Tietenberg, T., 2000, Environmental and natural resource economics, Addison Wesley, Reading, Massachusetts.

UN (United Nations) 1993a, Integrated Environmental and Economic Accounting, Interim version, Sales No. E. 93. XVII. 12. UN (United Nations), 1993b: Macroeconomic Data Systems, MSPA Data Bank of World Development Statistics, MSPA Handbook of World Development Statistics, MEDS/DTA/1 and 2 June, UN, New York, NY.

UN (United Nations), 1993c: UN MEDS Macroeconomic Data Systems, MSPA Data Bank of World Development Statistics, MEDS/DTA/1 MSPA-BK.93, Long-Term Socioeconomic Perspectives Branch, Department of Economic and Social Information \& and Policy Analysis, UN, New York, NY.

UN (United Nations), 1996, Annual Populations 19502050: The 1996 Revision, UN Population Division, United Nations, New York, NY. (Data on diskettes).

Watanabe, C., 2000, Industrial Dynamism and the Creation of a Virtuous Cycle between R\&D, Market Growth and Price Reduction The Case of Photovoltaic Power Generation (PV) Development in Japan, in: C.O. Wene, A. Voss and T. Fried (eds). Experience Curves for Policy Making: The Case of Energy Technologies, Proceedings IEA Workshop 10-11 May 1999, Stuttgart, Germany. 
Watanabe. C. and Griffy-Brown, C., 1999, Inter-firm technology spillover and the creation of a virtuous cycle between $\mathrm{R} \& \mathrm{D}$, market growth and price reduction; The case of photovoltaic power generation (PV) development in Japan. Paper presented at the International Workshop on Induced Technological Change and the Environment, IIASA, 21-22 June 1999, Laxenburg, Austria.

WCED (World Commission on Environment and Development), 1987, Our common future. Oxford University Press, Oxford.

World Bank, World Development Report, 1993: World Bank, Oxford University Press, New York, USA. 